\title{
Molecular genetics of bipolar disorder
}

\author{
NICK CR ADDOCK and IAN JONES
}

\begin{abstract}
Background A robust body of evidence from family, twin and adoption studies demonstrates the importance of genes in the pathogenesis of bipolar disorder. Recent advances in molecular genetics have made it possible to identify these susceptibility genes.
\end{abstract}

Aims To present an overview for clinical psychiatrists.

\section{Method Review of current molecular} genetics approaches and emerging findings.

Results Occasional families may exist in which a single gene plays a major role in determining susceptibility, but the majority of bipolar disorder involves more complex genetic mechanisms such as the interaction of multiple genes and environmental factors. Molecular genetic positional and candidate gene approaches are being used for the genetic dissection of bipolar disorder. No gene has yet been identified but promising findings are emerging. Regions of interest include chromosomes 4pl6, 12q23-q24, 16pl3, 21q22, and Xq24-q26. Candidate gene association studies are in progress but no robust positive findings have yet emerged.

\section{Conclusion It is almost certain that} over the next few years the identification of bipolar susceptiblity genes will have a major impact on our understanding of disease pathophysiology. This is likely to lead to major improvements and treatment in patient care, but will also raise important ethical issues.

\section{Declaration of interest Funding} detailed in Acknowledgements.
Clinicians have always known that bipolar disorder tends to run in families, but this observation - although of enormous academic interest - has had limited clinical import until now. Advances in molecular genetics have provided the tools needed to identify genes involved in conferring susceptibility to complex genetic disorders such as bipolar disorder.

In this review we will briefly describe the evidence for the involvement of susceptibility genes in bipolar disorder, then illustrate current molecular genetic approaches, providing examples from studies in which we have been personally involved. This paper is intended to be a readable overview of the topic for the general psychiatrist. Readers seeking a more rigorous and academic review should consult Craddock \& Jones (1999).

\section{FAMILY,TWIN AND ADOPTION STUDIES}

Several important features of the inheritance of bipolar illness will be familiar to all experienced clinicians:

(a) mood disorders often aggregate in families;

(b) the mode of inheritance is complex and does not usually follow simple Mendelian patterns (e.g. autosomal dominant, recessive, or sex-linked);

(c) within families multiply affected by mood disorder there is frequently a spectrum of illness phenotype, which may include unipolar depression, alcoholism, suicide or psychosis, in addition to bipolar disorder. A striking illustration of these three points is provided by the family trees of several famous and creative individuals with bipolar disorder, in Kay Redfield Jamison's fascinating book Touched by Fire (Jamison, 1993).

Although many family and twin studies of mood disorder have been undertaken in the past, it is only since the 1970s that researchers have used our modern understanding of bipolar illness. Epidemiological approaches have shown that for narrowly defined bipolar illness (i.e. bipolar I disorder) the life-time risk in most populations is $1 \%$ and is approximately similar in men and women (Smith \& Weissman, 1992). About 20 studies using the modern concept of bipolar disorder have examined the risk in first-degree relatives of a person with this disorder. Qualitatively, all studies indicate a marked increase in life-time risk of bipolar disorder in the first-degree relatives of the proband. Quantitative results vary between studies (according to methodology and method of ascertainment), with most estimating a risk 5-10 times that of the general population (Craddock \& Jones, 1999). It is important to appreciate that the life-time risk of unipolar major depression is also increased in the first-degree relatives of a person with bipolar disorder. Indeed, the absolute risk of unipolar depression is higher than the absolute risk of bipolar disorder in the first-degree relatives of a proband with bipolar illness. However, because the background population rate of unipolar depression is substantially greater than that of bipolar disorder $(10 \% v .1 \%)$, the relative increase in risk is much lower for unipolar disorder (of the order of a doubling of risk) (McGuffin \& Katz, 1989).

Six twin studies of bipolar disorder have shown an increased risk in monozygotic (identical) co-twins compared with dizygotic (fraternal) co-twins of a proband with bipolar disorder (Kringlen, 1967; Allen et al, 1974; Bertelsen et al, 1977; Torgersen, 1986; Kendler et al, 1993; Cardno et al, 1999). Again, the quantitative results vary, with most risk studies estimating the risk at 45-75 times that of the general population. Moreover, twin studies indicate that the majority of co-twins who do not develop narrowly defined bipolar illness will have some form of severe depression during their life, i.e. very few identical co-twins of an individual with bipolar disorder escape all affective morbidity. Hence, twin studies provide robust evidence for the importance of genes in bipolar disorder. However, these studies also demonstrate that genes are not the whole story - the fact that not all monozygotic twins are concordant for narrowly defined bipolar disorder indicates that genetically identical individuals are not necessarily destined to exhibit the same psychiatric phenotype. There have been only two adoption studies of bipolar disorder, 
neither of which was large - one had 30 probands (Mendlewicz \& Rainer, 1977), the other 10 (Wender et al, 1986) - but they both showed that the risk of bipolar illness is greater in biological relatives than in adoptive relatives of the probands.

Thus family, twin and adoption data are consistent in demonstrating the important role that genes play in susceptibility to bipolar illness. Equally, they show that factors other than straightforward genetics must also play a part, the twin concordance data being the most important evidence for this. Table 1 summarises approximate recurrence risk estimates for major affective disorder in various classes of relative of a proband with bipolar disorder.

\section{MODE OF INHERITANCE}

Having established that genes have a role in bipolar disorder, what sort of genetic model might we anticipate? One could postulate three extreme possibilities for a disease:

(a) a single gene model, where only one gene and nothing else plays a role;

(b) a polygenic model, where there are a huge number of genes which individually have a vanishingly small effect but together completely explain the illness;

(c) a purely environmental model, where genes have no role.

If you think about these theoretical models carefully, you will realise that virtually no illness that we know of conforms to any of the models. For example, it is now becoming clear that even classical singlegene illnesses such a cystic fibrosis have phenotypic modifiers, which may be genes or environmental factors. Similarly, most environmental factors involve an interaction with genotype. You may think that if a person is knocked over by a car it is a purely environmental event. However, people who stagger out of bars or public houses late at night in an intoxicated state are at much higher risk of being knocked down by a car. Genetics is known to influence many personality variables (Bouchard et al, 1990), and personality plays a major role in determining the probability that an individual will stagger out of a public house intoxicated. This leads to the clear recognition that this apparent environmental event actually represents a genotype-environment interaction.

Given these complexities in even apparently simple situations, it should not be surprising that current evidence suggests that the majority of bipolar illness does not conform to any of the three simple extremes but rather to an intermediate model. When one considers the recurrence risk data from classical genetic studies, the rapid drop-off in recurrence risk from monozygotic cotwins down to first-degree relatives and back to the general population cannot be explained by a single-gene model of bipolar illness, whereas it is consistent with several interacting genes, technically called epistasis (Craddock et al, 1995). This interaction could involve one gene of relatively major effect and several with a more minor effect, or several genes all having a modest effect. Alternatively, it could even be a large number of genes of small effect. In addition to the genetic effects, an unknown amount of environmental influence is almost certainly involved.

It remains possible that in some unusual families, illness may be determined primarily by a single gene; however, for the majority of bipolar illness in the population it is likely that several genes are involved. It is also important to recognise that we now know of various genetic mechanisms that do not follow simple Mendelian laws and that give complex patterns of inheritance. Examples include dynamic mutations such as expanding trinucleotide repeats (which occur in Huntington's disease and several other neurodegenerative disorders), imprinting and mitochondrial inheritance. It is possible - and indeed has been suggested

Table I Life-time risk of affective disorder in relatives of a person with bipolar disorder. The approximate lifetime risk of bipolar disorder and the additional life-time risk of unipolar depression are shown according to degree of the biological relationship to the proband. These figures represent estimates taken from studies conducted over the past 30 years that have used the modern concept of bipolar disorder (Craddock, 1995)

Life-time risk of bipolar disorder (\%) Life-time risk of unipolar disorder (\%)

\begin{tabular}{lcc}
\hline Monozygotic co-twin & $45-75$ & $15-25$ \\
First-degree relative & $4-9$ & $8-20$ \\
Unrelated & $0.5-1.5$ & $5-10$ \\
\hline
\end{tabular}

(e.g. McInnis et al, 1993; McMahon et al, 1995) - that such mechanisms could play a part in bipolar illness, and these possibilities must be entertained in molecular genetic studies (Craddock \& Owen, 1996).

\section{MOLECULAR GENETIC STUDIES}

Linkage and association studies using DNA markers are the cutting edge of modern psychiatric genetics (Craddock \& Owen, 1996). Linkage studies use families in which more than one member is affected by disease, whereas association studies use unrelated affected individuals and appropriate comparison individuals. Conceptually, molecular genetic studies can be divided into positional and candidate gene approaches. In positional approaches, the chromosomal locations of susceptibility genes are determined, usually by linkage studies. This requires no knowledge of disease pathophysiology and can be considered as a purely genetic approach. This has obvious attractions for study of psychiatric illnesses where pathogenesis is poorly understood. In contrast, the candidate gene approach presupposes that the researcher has sufficient understanding of disease biology to be able to recognise genes that may be involved in the disorder. These are then examined in linkage or association studies. In practice, both positional and candidate approaches are often combined, and it is likely that a positional candidate approach will be required to identify genes in complex diseases such as bipolar disorder (Collins, 1995).

\section{Linkage studies}

Researchers have been undertaking linkage studies in bipolar illness for a number of years. Initially, the focus was on identifying large affected families, an approach known to be useful in disorders following simple, single-gene modes of inheritance. Problems with this 'large family' approach (Craddock \& Owen, 1996) include the following:

(a) such families are rare - they are therefore difficult to recruit and are not representative of most bipolar disorder in the population;

(b) extended multiply-affected families typically have a broad spectrum of expression of illness, making it difficult to classify individuals on a simple affected/unaffected basis; 
(c) simple, single-gene inheritance does not occur, at least for the vast majority of cases of bipolar illness;

(d) the efficiency of the most relevant methods of statistical analysis in large families is severely compromised by uncertainty of the mode of inheritance;

(e) under plausible modes of inheritance, large families may actually be less powerful than small families for detecting the genes by linkage (Badner et al, 1998).

A more recent trend is to study smaller nuclear families, which are now recognised as being more useful for investigation of complex disease (Badner et al, 1998) and address issues (a) to (e) above. The main potential disadvantage of using smaller families is the large sample size required. An example is the Wellcome Trust Bipolar Sib Pair Genome Study being undertaken by N.C.'s group in collaboration with that of Dr Michael Gill at Trinity College, Dublin (Craddock \& Gill, 1999). In the first stage of this study 270 affected sib pairs were genotyped for 400 markers spanning the genome (i.e. all the chromosomes). Areas of interest from stage 1 are being followed in an expanded sample of 420 affected sib pairs. Several data-sets with large extended families and others with small nuclear families are now available and a great deal of work has been done and is being done by groups around the world in both types of family collection.

A number of chromosome locations are emerging in which evidence for linkage is provided by multiple data-sets. It is important, however, to emphasise that metaanalysis of linkage studies is non-trivial and it would not be appropriate to claim that any of the linkage findings have yet been replicated beyond reasonable doubt. An overview of linkage findings in bipolar disorder can be obtained from the collection of Chromosome Workshop reports from the Fifth World Congress of Psychiatric Genetics, Santa Fe, 1997 (Barden \& Morissette, 1998; Crowe \& Vieland, 1998; Gurling, 1998; Kennedy \& Macciardi, 1998; Levinson \& Coon, 1998; Nimgaonkar, 1998; Nurnberger \& Foroud, 1998; Owen \& Craddock, 1998; Paterson, 1998; Van Broeckhoven \& Verheyen, 1998; Wildenauer \& Schwab, 1998) and the Sixth World Congress of Psychiatric Genetics, Bonn, 1998 (Barden \& Morissette, 1999; Craddock \& Lendon, 1999; Crowe \& Vieland, 1999; Curtis, 1999; DeLisi \& Crow,
1999; Detera-Wadleigh, 1999; Gejman, 1999; Hallmayer, 1999; Kennedy et al, 1999; Nurnberger \& Foroud, 1999; Paterson, 1999; Schwab \& Wildenauer, 1999; Van Broeckhoven \& Verheyen, 1999; Wildenauer \& Schwab, 1999). Chromosome regions of interest include $4 \mathrm{p} 16$, 12q23-q24, 16p, chromosome 18, 21q22 and Xq24-q26.

Unusual families or cases can sometimes give important research clues. Such a family, which we have been investigating in collaboration with Mike Owen's group in Cardiff, is pedigree 324 (Fig. 1) in which several members had a skin disease called Darier's disease, together with major affective disorder (Craddock et al, 1994). Darier's disease is a rare autosomal dominant condition (Burge \& Wilkinson, 1992). In the pedigree, the mother and five out of eight offspring had both Darier's disease and severe affective illness, whereas the father and three out of eight offspring had neither illness (Craddock et al, 1994). This pedigree is shown in Fig. 1. Individual 2.6 was bipolar; 1.2 had 40 admissions with depression; individuals 2.1 and 2.2 both had severe recurrent depression; individual 2.8 committed suicide; and individual 2.7 had depression following childbirth.

Although there are a number of possible explanations for a mood disorder occurring together with a skin disease, the most likely explanation for this co-segregation is that a susceptibility gene for bipolar illness lay near the gene for Darier's disease and that within this family the two genes were in linkage and segregated together. The formal genetic evidence in favour of this hypothesis is a log likelihood ratio (lod) score of 2.1, which although not considered conclusive is certainly interesting. The importance of this family is that it pinpoints the region of the Darier's disease

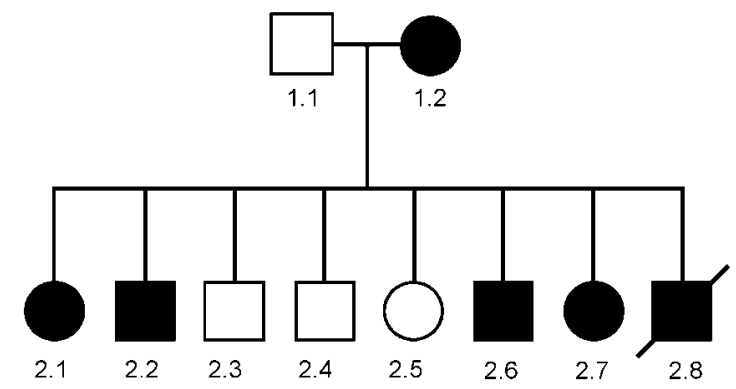

Fig. I Genogram of pedigree 324. Square symbols are used for males, circles for females. A diagonal line indicates that the subject is dead. A solid symbol indicates that the subject is affected by both Darier's disease and major affective disorder. This pedigree was reported in detail in Craddock et al (1994); however, the affective status of subject 2.8 has changed during the subsequent period of observation. gene as a locus to investigate in other bipolar pedigrees. Thus, after the chromosomal location of the Darier's gene was mapped to chromosome 12q23-q24.1 (Craddock et al, 1993), we studied linkage of bipolar disorder in 45 bipolar pedigrees (none of which had any members with Darier's disease). Modest evidence was obtained in support of linkage across the Darier's disease region, with maximum lod scores of approximately 2 (Dawson $e t$ $a l, 1995)$, certainly consistent with the existence of a bipolar susceptibility gene in this region.

Linkage of bipolar disorder to the Darier's disease region was also demonstrated in an independent study by Barden et al (1996). From a genetic isolate of French origin, which included 130 members, many of whom were affected by bipolar mood disorder, a lod score in excess of 3 was obtained in the region of the Darier's disease gene on chromosome 12q. This group has extended the pedigree and with further genotyping, the lod score in the Darier's region is currently 5 . This constitutes extremely impressive evidence in favour of linkage. More recent data from other groups have provided further support for the existence of a susceptibility gene in this region (Ewald et al, 1998), although the region of interest spans approximately 40 centimorgans. In addition, we have now identified another family, pedigree 5501, in which bipolar illness and Darier's disease co-segregate and in which the maximum evidence for linkage between mood disorder and genetic markers at the Darier's disease locus is a lod score of 3.7 (Jones et al, 1999).

We are currently undertaking dense marker genotyping across this chromosome region to search for linkage disequilibrium, which would allow the susceptibility gene 
to be localised to within approximately 1 megabase. In addition, candidate gene analysis is also being used and a number of candidates in this region have been examined, including PLA2 (Jacobsen et al, 1997), trinucleotide repeat-containing loci such as ASH1 and SCA2 (Franks et al, 1999), and the Darier's gene itself (Sakuntabhai et al, 1999; Jacobsen et al, 1999a,b).

\section{Association studies}

The original association study approach uses unrelated bipolar cases and unrelated comparison individuals (controls) who are matched for potentially relevant variables such as gender, ethnicity and age. An increasingly popular refinement is to use a family-based association paradigm in which DNA is obtained from a proband with bipolar disorder and both biological parents. The non-transmitted parental alleles are used as a notional control, and this approach avoids many of the problems of population stratification that can be obtained with conventional case-control studies (Falk \& Rubinstein, 1987). Many groups around the world are using both case-control and family-based association approaches to undertake linkage disequilibrium and candidate gene studies.

An example of the candidate gene association approach is the recent work we undertook in collaboration with Dr George Kirov and Professor Michael Owen (University of Wales College of Medicine, Cardiff) to investigate the possible relationship between catechol-O-methyl transferase (COMT), an enzyme involved in the breakdown of catecholamines, and rapid cycling. An amino acid polymorphism in the gene, Val $\rightarrow$ Met at position 108 , determines high and low activity of the enzyme. The COMT gene lies in the region of chromosome $22 \mathrm{q}$ commonly deleted in velo-cardio-facial syndrome. Lachman et al (1996) studied approximately 20 subjects with this syndrome and found that many had rapid-cycling mood disorder, all of whom possessed the low-activity allele of the COMT gene. These researchers proposed that this low-activity allele may be associated with rapid cycling in the more general population of patients with bipolar disorder.

To test this hypothesis, we examined our sample of 755 participants conforming to the DSM-IV (American Psychiatric Association, 1994) bipolar disorder diagnosis and classified them according to the presence or absence of rapid cycling (Kirov et al, 1998). This classification is straightforward for definite rapid cycling because if a reasonable amount of information is available, you can be sure that the individual meets the diagnostic criteria for cycling. Using these criteria, 55 patients were identified as having the rapid-cycling form of the disorder. Identifying definite non-rapidcycling subjects is much more difficult because a substantial amount of information is required to provide convincing evidence that the person has never suffered from rapid cycling. Using these stringent criteria, 110 patients were identified as having a definite non-rapid-cycling course. Genotyping results are shown in Fig. 2, which also includes results for a total sample of subjects with bipolar disorder (unselected for rapid cycling) and a comparison group of individuals without bipolar disorder. Compared with the controls, there was very little difference in allele frequency in the whole bipolar disorder group, which suggests that the COMT gene is not a susceptibility gene for bipolar disorder. However, consistent with the hypothesis of Lachman et al (1996), the low-activity allele was significantly more common in the rapid-cycler group compared with the non-rapid-cycler group ( $P=0.0120$. Furthermore, there is a dose-dependent effect in genotype distribution such that an individual with more copies of the low-activity allele has a greater likelihood of having a rapid-cycling disorder. Thus, the evidence is consistent with COMT acting as a potential course modifier rather than as a susceptibility gene. However, it is important to stress that this finding should be treated as preliminary unless, and until, it is replicated in large independent samples.

Another example of use of the association approach and the importance of thorough phenotypic (i.e. clinical) characterisation is provided by our work on bipolar affective puerperal psychosis. Many women with bipolar disorder are susceptible to puerperal triggering of episodes (Brockington, 1996). It is widely believed that steroid hormones (particularly oestrogens) are involved in the triggering process and there is evidence that susceptibility to the trigger is familial, probably genetic (Jones et al, 2000). Thus, neuronally relevant genes influenced by oestrogens are plausible candidates as susceptibility genes for bipolar affective puerperal psychosis. In a case-control study of 96 women with bipolar disorder who experienced puerperal episodes starting within 2 weeks of parturition, we found that variation at the serotonin transporter gene (a major site of action of many antidepressants) has a significant $(P<0.008)$, substantial (odds ratio 4$)$ and important (population attributable fraction $69 \%$ ) influence on susceptibility to bipolar affective puerperal episodes (Coyle et al, 2000). As with the COMT results, it is important that this finding receives independent confirmation.

\section{PSYCHOSOCIAL AND ETHICAL ISSUES}

Identification of susceptibility and modifying genes for bipolar disorder has the potential to radically change the practice of



Fig. 2 Distribution of alleles of the gene for catechol-O-methyl transferase (COMT) in patients with bipolar disorder and comparison subjects, taken from data published by Kirov et al (1998). White bars represent the high-activity allele, black bars the low-activity allele. RC, rapid-cycling bipolar group $(n=55)$; Non-RC, nonrapid-cycling bipolar group ( $n=I 10)$; Total BP, total sample of subjects with bipolar disorder $(n=4 \mid 2)$; Controls, comparison subjects unaffected by bipolar disorder $(n=368)$ used in previous study of the COMT polymorphism (BIOMED European Bipolar Collaborative Group, 1997). 
psychiatry, alter the perception of mental illness and greatly enhance the understanding and treatability of some of the common major illnesses that afflict populations around the world (Craddock \& Owen, 1996). Such advances will also be accompanied by important ethical and psychosocial issues (Jones \& Craddock, 1997, 1998), including availability of new technology, access to genetic information and the subtle shift from a simple doctor-patient relationship to a doctor-patient-family relationship. An interesting question concerns the attitude of patients, relatives, professionals and the general public towards the possible development of genetic tests that may help in directing treatment or prophylaxis of bipolar disorder. We have undertaken a questionnaire study examining attitudes among (a) patients with bipolar disorder attending a lithium clinic, (b) patients and relatives in families multiply affected by bipolar disorder, (c) general practice attendees unselected for psychiatric morbidity, and (d) psychiatrists in training (further details available from N.C. upon request). All groups strongly favoured the availability of such tests in adults, although it is of interest that the psychiatrists were significantly more cautious than the other groups. This and many other psychosocial and ethical issues require investigation in parallel with the current molecular genetic studies.

\section{CONCLUSION}

A robust body of genetic data indicates the existence of susceptibility genes in bipolar disorder. The current positional and candidate molecular genetic studies are producing promising results although no susceptibility gene has yet been identified. It is likely that several, perhaps many, susceptibility genes will be discovered in the next few years and this will greatly enhance our understanding of disease pathogenesis. It is likely that this will lead to a revolution in clinical psychiatry which will benefit psychiatrists, patients and their families. It is also extremely important to recognise that there are a number of ethical issues that are going to accompany these developments; these will need to be considered very carefully.

\section{ACKNOWLEDGEMENTS}

We thank our research collaborators at the University of Wales College of Medicine, Cardiff (Mike Owen, Mick O'Donovan, George Kirov, Nick Jacobsen, Emily Franks), the Institute of Psychiatry,
London (Peter McGuffin) and Trinity College, Dublin (Michael Gill).We are indebted to the Wellcome Trust for providing personal support and to both the Wellcome Trust and South Birmingham Mental Health Trust for research support. Finally, we would like to thank the many patients, families and professionals who have contributed to this research.

\section{REFERENCES}

Allen, M. G., Cohen, S., Pollin, W., et al (1974)

Affective illness in veteran twins: a diagnostic review. American Journal of Psychiatry, I3I, 1234-1239.

American Psychiatric Association (1994) Diagnostic and Statistical Manual of Mental Disorders (4th edn) (DSM-IV). Washington, DC: APA

Badner, J. A., Gershon, E. S. \& Goldin, L. R. (1998) Optimal ascertainment strategies to detect linkage to common disease alleles. American Journal of Human Genetics, 63, 880-888.

Barden, N. \& Morissette, J. (1998) Chromosome I3 workshop. Psychiatric Genetics, 8, 93-96.

_ \& _ (1999) Chromosome 13 workshop report. American Journal of Medical Genetics, 88, 260-262.

\section{_ , Plante, M., Rochette, D., et al (1996) Genome-} wide microsatellite marker linkage study of bipolar affective disorders in a very large pedigree derived from a homogeneous population in Quebec points to susceptibility locus on chromosome 12. Psychiatric Genetics, 6, 145.

Bertelsen, A., Harvald, B. \& Hauge, M. (1977) A Danish twin study of manic-depressive disorders. British Journal of Psychiatry, I30, 330-35I.

\section{BIOMED European Bipolar Collaborative Group} (1997) No association between bipolar disorder and alleles at a functional polymorphism in the COMT gene. British Journal of Psychiatry, 170, 526-528.

Bouchard, T. J., Lykken, D. T., McGue, M., et al (1990) Sources of human psychological differences: the Minnesota study of twins reared apart. Science, $\mathbf{2 5 0}$ 223-228.

Brockington, I. F. (1996) Motherhood and Menta Health, p. 612. Oxford: Oxford University Press.

Burge, S. M. \& Wilkinson, J. D. (1992) Darier-White disease: a review of the clinical features in 163 patients. Journal of the American Academy of Dermatology, 27 $40-50$

Cardno, A. G., Marshall, E. J., Coid, B., et al (1999) Heritability estimates for psychotic disorders. Archives of General Psychiatry, 46, 867-782.

Collins, F. S. (1995) Positional cloning moves from perditional to traditional. Nature Genetics, 9, 347-350.

Coyle, N., Jones, I., Robertson, E., et al (2000) Variation at the serotonin transporter gene influences susceptibility to bipolar affective puerperal psychosis. Lancet, 356, |490-|49|.

Craddock, N. (1995) Genetic linkage and association studies of bipolar disorder. PhD thesis: University of Wales College of Medicine.

_ \& Gill, M. (1999) The Wellcome Trust UK -Irish bipolar sib pair study: first stage genome screen. Molecular Psychiatry, 4, S2I.

_ \& Jones, I. (1999) The genetics of bipolar disorder. Journal of Medical Genetics, 36, 585-594.

— \& Lendon, C. (1999) Chromosome workshop: chromosomes II, 14, and 15. American Journal of Medical Genetics, 88, 244-254.
_ \& Owen, M. J. (1996) Modern molecular genetic approaches to psychiatric disease. British Medical Bulletin, 52, 434-452.

_ , Dawson, E., Burge, S., et al (1993) The gene for Darier's disease maps to chromosome 12q23-q24.I. Human Molecular Genetics, 2, 194I-1943.

_, Owen, M., Burge, S., et al (1994) Familial cosegregation of major affective disorder and Darier's disease (keratosis follicularis). British Journal of Psychiatry, 164, 355-358.

Khodel, V., Van Eerdewegh, P., et al (1995)

Mathematical limits of multilocus models: the genetic transmission of bipolar disorder. American Journal of Human Genetics, 57, 690-702.

Crowe, R. R. \& Vieland, V. (1998) Chromosome workshop. Psychiatric Genetics, 8, 73-78.

_ \& _ (1999) Report of the chromosome 5 workshop of the Sixth World Congress on Psychiatric Genetics. American Journal of Medical Genetics, 88, 229-232.

Curtis, D. (1999) Chromosome 21 workshop. American Journal of Medical Genetics, 88, 272-275.

Dawson, E., Parfitt, E., Roberts, Q., et al (1995) Linkage studies of bipolar disorder in the region of the Darier's disease gene on chromosome 12q23-24. American Journal of Medical Genetics (Neuropsychiatric Genetics), 60, 94-102.

DeLisi, L. E. \& Crow, T. J. (1999) Chromosome workshops 1998: current state of psychiatric linkage. American Journal of Medical Genetics, 88, 215-218.

Detera-Wadleigh, S. D. (1999) Chromosomes 12 and 18 workshop. American Journal of Medical Genetics, 88 255-259.

Ewald, H., Degn, B., Mors, O., et al (1998) Significant linkage between bipolar affective disorder and chromosome 12q24. Psychiatric Genetics, 8, I31-140.

Falk, C. T. \& Rubinstein, P. (1987) Haplotype relative risks: an easy and reliable way to construct a proper control sample for risk calculations. Annals of Human Genetics, 5I, 227-233.

Franks, E., Guy, C., Jacobsen, N., et al (1999) Eleven trinucleotide repeat loci that map to chromosome 12 excluded from involvement in the pathogenesis of bipolar disorder. American Journal of Medical Genetics (Neuropsychiatric Genetics), 88, 67-70.

Gejman, P.V. (1999) Chromosomes 19 and 20 report. American Journal of Medical Genetics, 88, 27I.

Gurling, H. (1998) Chromosome 21 workshop Psychiatric Genetics, 8, I09-113.

Hallmayer, J. (1999) Chromosomes I, 2 and 7 workshop. American Journal of Medical Genetics, 88 219-223.

Jacobsen, N., Daniels, J., Moorhead, S., et al (1997) Association study of bipolar disorder at the phospholipase A2 gene (PLA2A) in the Darier's disease (DAR) region of chromosome 12q23-q24.I. Psychiatric Genetics, 6, 195-199.

Franks, E. K. E, Owen, M. J., et al (1999a)

Mutational analysis of phospholipase A2A: a positional candidate susceptibility gene for bipolar disorder. Molecular Psychiatry, 4, 274-279.

_ , Lyons, I., Hoogendoorn, B., et al (1999b) ATP2A2 mutations in Darier's disease and their relationship to neuropsychiatric phenotypes. Human Molecular Genetics, 8, 1631-1636.

Jamison, K. R. (1993) Touched by Fire. New York: Free Press/Macmillan.

Jones, I. \& Craddock, N. (1997) The crisis in psychiatry (letter). Lancet, 349, 1550. 
_ \& _ (1998) Ethical issues in genetics of mental disorders (letter). Lancet, 352, 1788.

_ , McCandless, F., Morey, J., et al (1998) Molecular genetic approaches to puerperal psychosis. American Journal of Medical Genetics, 8I, 544.

_, Owen, M. J. \& Craddock, N. (1999) Further evidence of familial cosegregation of major affective disorder and Darier's disease. Molecular Psychiatry, 4 S73.

_ , Middle, F., Lendon, C., et al (2000) Molecular genetic studies of bipolar disorder and puerperal psychosis at two polymorphisms in the estrogen receptor $\alpha$ gene (ESR I). American Journal of Medical Genetics (Neuropsychiatric Genetics), 96, 850-853.

Kendler, K. S., Neale, M., Kessler, R., et al (1993) A twin study of recent life events and difficulties. Archives of General Psychiatry, 50, 789-796.

Kennedy, J. L. \& Macciardi, F. M. (1998) Chromosome 4 workshop. Psychiatric Genetics, 8, 67-7l.

\section{_, Basile, V. S. \& Macciardi, F. M. (1999)}

Chromosome 4 workshop summary: Sixth World

Congress on Psychiatric Genetics, Bonn, Germany,

October 6-10. American Journal of Medical Genetics, 88 224-228.

Kirov, G., Murphy, K. C., Arranz, M. J., et al (1998) Low activity allele of catechol-O-methyltransferase gene associated with rapid cycling bipolar disorder. Molecular Psychiatry, 3, 342-345.

Kringlen, E. (1967) Heredity and Environment in the Functional Psychoses. London: Heinemann.

Lachman, H. M., Morrow, B., Shprintzen, R., et al (1996) Association of codon I08/158 catechol-O methyltransferase gene polymorphism with the psychiatric manifestations of velo-cardio-facial syndrome. American Journal of Medical Genetics (Neuropsychiatric Genetics), 67, 468-472.

Levinson, D. F. \& Coon, H. (1998) Chromosome 22 workshop. Psychiatric Genetics, 8, II5-120.

McGuffin, P. \& Katz, R. (1989) The genetics of depression and manic-depressive disorder. British Journal of Psychiatry, I55, 294-304.

McInnis, M. G., McMahon, F. J., Chase, G. A., et al (1993) Anticipation in bipolar affective disorder. American Journal of Human Genetics, 53, 385-390.

McMahon, F. J., Stine, O. C., Myers, D. A., et al (1995) Patterns of maternal transmission in bipolar affective disorder. American Journal of Human Genetics, 58, 1277-1286

Mendlewicz, J. \& Rainer, J. D. (1977) Adoption study supporting genetic transmission in manic-depressive illness. Nature, 268, 327-329.

Nimgaonkar, V. L. (1998) Chromosome 3 workshop. Psychiatric Genetics, 8, 63-65.

Nurnberger, J. I. \& Foroud, T. (1998) Chromosome 6 workshop. Psychiatric Genetics, 8, 79-83.

\section{CLINICAL IMPLICATIONS}

- Molecular genetics provides powerful tools for investigating neuropsychiatric disorders.

- Identification of bipolar susceptibility genes will contribute to improved treatment and patient care.

- Improved understanding of disease pathogenesis has the potential to revolutionise the practice of clinical psychiatry.

\section{LIMITATIONS}

- No bipolar susceptibility gene has yet been identified.

- Understanding of disease pathogenesis will require dissection of the complex interaction between genetic and environmental factors.

- Major advances will raise important ethical issues that will need to be considered carefully.

NICK CRADDOCK, PhD, IAN JONES, MRCPsych, Division of Neuroscience, University of Birmingham, UK

Correspondence: Professor Nick Craddock, Professor of Molecular Psychiatry and Head of Department, Department of Psychiatry, University of Birmingham, Queen Elizabeth Psychiatric Hospital, Birmingham BI5 2QZ, UK. Tel: +44 (0) I2I 678 2358; fax +44 (0) I2I 678 235I ; e-mail: n.craddock@bham.ac.uk

_ \& _ (1999) Chromosome 6 workshop report. American Journal of Medical Genetics, 88, 233-238.

Owen, M. J. \& Craddock, N. (1998) Chromosome II workshop. Psychiatric Genetics, 8, 89-92.

Paterson, A. D. (1998) $X$-chromosome workshop. Psychiatric Genetics, 8, 121-126.

_ (1999) Sixth World Congress of Psychiatric Genetics $\times$ Chromosome Workshop. American Journal of Medical Genetics, 88, 279-286.

Sakuntabhai, A., Ruiz-Perez, V., Carter, S., et al (1999) Mutations in ATP2A2, encoding a Ca2+ pump, cause Darier disease. Nature Genetics, 2I, 27I-277.

\section{Schwab, S. G. \& Wildenauer, D. B. (1999)}

Chromosome 22 workshop report. American journal of Medical Genetics, 88, 276-278.

Smith, A. L. \& Weissman, M. M. (1992) Epidemiology In Handbook of Affective Disorders (2nd edn), pp. III-129. Edinburgh: Churchill Livingstone.
Torgersen, S. (1986) Genetic factors in moderately severe and mild affective disorders. Archives of General Psychiatry, 43, 222-226.

Van Broeckhoven, C. \& Verheyen, G. (1998) Chromosome 18 workshop. Psychiatric Genetics, 8 , 97-108

_ \& _ (1999) Report of the chromosome 18 workshop. American Journal of Medical Genetics, 88 263-270.

Wender, P. H., Kety, S. S., Rosenthal, D., et al (1986) Psychiatric disorders in the biological and adoptive families of adopted individuals with affective disorders. Archives of General Psychiatry, 43, 923-929.

Wildenauer, D. B. \& Schwab, S. G. (1998) Chromosome 8 workshop. Psychiatric Genetics, 8 , 85-87.

_ \& - (1999) Chromosomes 8 and 10 workshop. American Journal of Medical Genetics, 88, 239-243. 